\title{
Influence of a Walking Aid on Temporal and Spatial Parameters of Gait in Healthy Adults
}

Prasath Jayakaran, MPT, Lorraine DeSouza, PhD, John Cossar, MSc, Kenneth Gilhooly, PhD

P.J. Centre for Research in Rehabilitation,

School of Health Sciences and Social Care,

Bentre for Health, Londin, United Kingdom

Research, School of Physiotherapy, University

of Otago, New Zealand. Address correspondence

to: P.J.; e-mail: prasath.jayakaran@

Disclosure: nothing to disclose

L.D. Centre for Research in Rehabilitation,

School of Health Sciences and Social Care,

Brunel University, London, United Kingdom

Disclosure: nothing to disclose

J.C. Centre for Research in Rehabilitation,

School of Health Sciences and Social Care,

Brunel University, London, United Kingdom

Disclosure: nothing to disclose

K.G. Centre for Research in Rehabilitation,

Brunel University, Londond Social Care,

Disclosure: nothing to disclose

2013; accepted February 6, 2014

PM\&R

1934-1482/14/\$36.00

Printed in U.S.A

\section{ABSTRACT}

Objective: To determine the effect of using a walking aid on temporal and spatial parameters of gait when used for balance versus support on the dominant and non-dominant hand side.

Design: Repeated measures observational study design

Setting: University gymnasium.

Participants: Twenty-seven healthy male and female adults of mean (standard deviation) age $44.74 \pm 10.00$ years.

Methods: Five walking conditions (C) were completed by all participants on the GAITRite pressure mat. Normal walking (C1), walking with a cane in the dominant hand (C2) and non-dominant hand (C3) as if using for balance, walking with a cane in the dominant hand (C4) and non-dominant hand (C5) while allowing approximately 10\% of the body weight through the cane.

Main Outcome Measurements: Temporal measurements as a percentage of a gait cycle (swing time, stance time, single support time, double support time) and the base of support for the left and the right foot for all 5 walking conditions. 
Results: A significant difference $(\mathrm{P}<.001)$ was observed between $\mathrm{C} 1, \mathrm{C} 2$, and $\mathrm{C} 3$ in percentage swing time and percentage stance time on the ipsilateral side, and in percentage single limb support for the contralateral side. The double limb support time was significantly different (P $<.04)$ for both ipsilateral and contralateral sides. Comparisons among C1, C4, and C5 demonstrated significance ( $<.001)$ for all variables. Post hoc analysis showed Q1 significance between C1 and C4, C1 and C5 for all variables except percentage stance time on the ipsilateral side and percentage single limb support on the contralateral side.

Conclusions: The use of walking aids for balance modifies the swing and stance parameters of the ipsilateral side and does not affect the base of support formed by the feet in healthy adults. When used for support, walking aids alter the swing and stance parameters, and also the base of support formed by the feet.

\section{INTRODUCTION}

The prescription of mobility or walking aids is often necessary to provide support or to supplement balance [1]. A recent estimate indicates that 30.6 million people who live in the United States have difficulty with mobility that requires use of a walking aid [2]. Walking aids may be used to increase balance ability, thereby increasing balance confidence and decreasing frequency of falling [3]. However, when used as a support, they may reduce the weight loading on the affected limbs [4]. Generally, determination of ipsilateral or contralateral use of a walking aid in clinical populations is based on factors such as the level and the side of most instability, pain, or weakness [5,6]; whereas, when used for balance, the side of use may depend more on the individual's preference [7]. For example, in people with unilateral hip pain or dysfunction,

a walking aid when held on the contralateral side and advanced along with the affected limb effectively offloads the affected hip [8,9] and also replicates a reciprocal walking pattern. However, when used for balance, the side of use may depend on the convenience or hand preference of the individual [7,10,11].

Although walking aids are frequently used for different clinical populations $[9,12,13]$, there is a lack of quantitative data on how they may influence gait. A few studies have explored the impact of different types of walking aids on gait in healthy [14] and clinical population [13], and other studies that detailed the muscle activation patterns in upper [15] and lower limbs [8,9]. However, the objective evidence of the effect of walking aids on key temporospatial gait parameters

is limited. The aim of this study was to determine the effect of using a walking aid on the temporal and spatial parameters of gait when used for balance versus support on the dominant or non-dominant hand side.

\section{METHODS}

\section{Participants}

A convenience sample of male and female volunteers ages 18 years and older was recruited from the University staff cohort. Selection was based on the self-declared ability to complete repeated $20-\mathrm{m}$ walks without aids, within a short

period of time. Exclusion from the study was based on participants having a history of trauma to the lower limbs within the past year, a known balance disorder, or current pain in any part of the body that could potentially affect walking. The study was approved by the School Ethics Committee, and all the participants provided written informed consent before participation.

\section{Equipment and Setting}

The GAITRite Electronic walkway system was used to measure the gait parameters. The system includes a portable 8.8-m roll-up pressure mat and accompanying software, version 4.0; the sampling frequency of the data was $120 \mathrm{~Hz}$. Through a grid of pressure sensors, the system identifies the location and timing of each footfall and processes the spatiotemporal parameters from these data. The GAITRite system has previously been used in both clinical [16] and nonclinical populations [17], and the measurements have been reported to have acceptable psychometric properties in healthy adults $[17,18]$. For the purposes of this study, a height adjustable single-point aluminium cane was 
used by all the participants when completing the walking tasks. Five walking tasks were used to selectively test the effects of the cane when used for support versus balance, and when used in the dominant or non-dominant hand. The study was completed within a large gymnasium, which provided adequate space for use of the GAITRite system.

Tasks

Five different walking conditions $(\mathrm{C})$ that were determined to be useful to address the aims of the study were

- Condition $1(\mathrm{C} 1)$. Normal comfortable walking at self selected pace without any aids.

- Condition 2 (C2). Comfortable self-selected pace of walking while using a cane on the dominant hand side as if using for balance.

- Condition 3 (C3). Comfortable self-selected pace of walking while using a cane on the non-dominant hand side as if using for balance.

- Condition 4 (C4). Comfortable self-selected pace of walking while holding a cane on the dominant hand side and allowing approximately $10 \%$ of the body weight through the cane.

- Condition 5 (C5). Comfortable self-selected pace of walking while holding a cane on the non-dominant hand side and allowing approximately $10 \%$ of the body weight through the cane.

$\mathrm{C} 2$ and $\mathrm{C} 3$ were considered as balance conditions in which the cane was held and touched the ground in a reciprocal pattern without any weight transfer through the cane. C4 and $\mathrm{C} 5$ were determined as support conditions in which the cane was used as a supplement to transfer at least $10 \%$ of body weight through the cane.

\section{Measurements}

The measurements and their operational definitions are as follows; cadence (the number of steps/min), \% swing time (the duration between the last contact of the current foot fall and the first contact of the next footfall on the ipsilateral foot, expressed as percentage of gait cycle), \% stance time (the time elapsed between the first and last contact of the ipsilateral foot, expressed as percentage of gait cycle), \% single support time (the time between the last contact of the current foot fall and the first contact of the next foot fall of the ipsilateral foot, expressed as percentage of gait cycle), $\%$ double support time (the time when both feet were on the floor, which includes initial and terminal double support periods; the double support time of the left foot is the summation of double support during heel strike and toe off of the left foot vice versa for the right foot, expressed as percentage of gait cycle), and the base of support (the area of the ipsilateral foot and 1 foot fall of the contralateral foot, in cm). All the measurements except cadence were estimated separately for the left foot and the right foot, and were averaged over all included foot falls in a trial.

\section{Procedure}

All the participants completed a questionnaire to obtain their demographic details and to determine their eligibility to participate in the study. The Edinburgh Handedness Inventory was used to determine hand preference [19]. An Edinburgh Handedness Inventory score of $\geq 80$ is determined to be right dominant, whereas a score of less than or equal to -80 is determined to be left dominant, and scores between 80 and -80 are considered to be mixed-handed individuals [20]. For participants who demonstrated mixed handedness, the hand used for writing activity was considered as the dominant side. Foot dominance was determined by using the Otago Footedness Inventory [21]. The participants completed at least 1 practice trial and 3 actual trials for each of the conditions in a random order determined for each participant before commencement of the study. Practice trials were given as appropriate to accustom the participants to the task. For walking conditions that involved the cane (C2 to C5), all the participants were trained and encouraged to replicate a reciprocal upper and lower limb movement pattern. All the participants completed the trials while wearing a pair of trainers or an equivalent comfortable foot wear. For $\mathrm{C} 4$ and $\mathrm{C} 5$, the participants were trained to load the cane with $10 \%$ of their body weight when standing. A weighing scale was used to provide visual feedback during the training. After training, the participants were tested on their ability to independently reproduce $10 \%$ loading without the use of feedback before undertaking $\mathrm{C} 4$ and $\mathrm{C} 5$. While undertaking $\mathrm{C} 4$ and $\mathrm{C} 5$, the participants were encouraged to reproduce the loading on the cane as practiced while standing 


\section{Data Processing}

The software application that accompanies the GAITRite system was used to process and determine the outcome measurements. The sensor activation due to the pressure through the cane was removed manually for each trial. The

sensor activation due to foot falls were retained for the estimation of the temporal and spatial measurements. Each

trial consisted of at least 8 foot falls. The average of all right foot falls and the average of all left foot falls of each trial were taken as the summary measurement of the right foot and left foot, respectively.

\section{Data Analysis}

The mean of 3 trials of each condition was determined and retained for further analysis. For the conditions for using a

cane, each of the left and right side measurements were categorized as the side ipsilateral and contralateral to the cane. A 1-way repeated measures analysis of variance was used to determine the statistical significance between normal comfortable walking and use of the cane on the dominant side and on the non-dominant side in 2 cane conditions (balance and support). Post hoc analyses for significant findings were performed by using Bonferroni corrections for multiple comparisons. The significance ( $\alpha$ level) was set at $\mathrm{P}<.05$, and all statistical tests were performed with the IBM SPSS Statistical Package 20 for Windows (SPSS Inc, Chicago, IL).

\section{RESULTS}

A total of 27 participants met the selection criteria and completed the study. The mean ( \pm standard deviation) age and body mass index of the participants was $44.74 \pm 10.00$ years and $25.94 \pm 4.01 \mathrm{~kg} / \mathrm{m}^{2}$, respectively. As measured by the Edinburgh Handedness Inventory, 20 participants demonstrated strong right hand dominance, whereas only 2 participants

were strong left hand dominant. The remaining 5 participants showed a mixed-hand preference. Twenty-three participants were strongly right footed, and 4 were strongly left footed, as measured by the Otago Footedness Inventory. The descriptive statistics of all the variables for the 5 conditions are as shown in Table 1 . The repeated measures analysis of variance (Table 2) demonstrated significant differences $(\mathrm{P}<.001)$ between normal walking $(\mathrm{C} 1)$ and for balance conditions $(\mathrm{C} 2$, $\mathrm{C} 3)$ in $\%$ swing time and \% stance time on the ipsilateral side, and in \% single limb support for the contralateral side. The double limb support was significant (P $\leq .04)$ for both ipsilateral and contralateral sides. Post hoc analysis showed differences between normal walking and dominant hand cane-assisted walking, normal walking and non-dominant hand caneassisted walking but not between dominant and non-dominant hand cane assisted walking.

Comparisons between normal walking (C1) and support conditions (C4, C5) demonstrated significance $(\mathrm{P}<.001)$ for all variables. Post hoc analysis showed significance between $\mathrm{C} 1$ and $\mathrm{C} 4, \mathrm{C} 1$ and $\mathrm{C} 5$ for all variables except \% stance time on the ipsilateral side and \% single limb support on the contralateral side, in which the difference was identified only between $\mathrm{C} 1$ and $\mathrm{C} 4$.

\section{DISCUSSION}

The primary purpose of this study was to determine the effect of walking aids on key temporal and spatial parameters of gait, when used for balance or support in healthy adults. It was found that the use of a walking aid significantly changed gait parameters when used for balance or support. 


\section{Balance and Support}

The differences identified by the current investigation in the swing time and stance time of the ipsilateral side when using the walking aids for balance are similar to previous findings with healthy subjects $[14,22]$. The current study identified a

significant difference in the single limb support time of the contralateral side and the double limb support time of both limbs. Single limb support is the time between the last contact of 1 foot to the first contact of the opposite foot [23].

The use of a cane on 1 side increased the swing time of the same side, which in turn increased the single limb support of the opposite side. However, the decrease in double limb support, which is the duration when both feet are on the ground, may have been due to decreased stance time on the ipsilateral side. No difference was identified in the base of support when using a cane for balance, which suggests that a cane used for balance may only modify the swing and stance

phases of the limb but not the base of support formed by the feet.

Generally, the estimation of the base of support in cane walking includes not only the feet but also the cane [5], but the base of support estimated by GAITRite in the current study excluded the cane. Therefore, the functional base of support when walking with the cane may have been wider than the base of support formed by the feet only. When the cane was used for support significant differences were observed for all the variables. As expected, changes were significant for the swing time, stance time, single and double limb support time. It was apparent that transfer of $10 \%$ body weight through the cane not only decreased the weight accepted on the contralateral side but also required additional time, which in turn modified other temporal parameters. This finding also was supported by the significant difference observed for the cadence in support conditions.

A significant decrease in the width of the base of support also was observed when compared with normal walking, which is contrary to the common understanding that the base of support increases in an unsteady and challenging gait [24,25]. Although the narrow walkway can be considered as one of the reasons that the participants decreased their interfoot distance to accommodate the cane, the non-significant difference seen in the balance condition negates this assumption. Alternatively, the participants may have demonstrated decreased interfoot distance so as to maintain the center of gravity within a controllable range when using a walking aid for support. However, this speculation needs to be further verified.

\section{Dominance and Non-dominance}

Hand dominance did not have any effect on gait parameters when used for balance; however, it did show some influence

when used for support. The use of a walking cane on the dominant side did change the ipsilateral swing time, stance time, and single limb support when compared with normal walking, but there was no difference on the non-dominant side. For the support conditions, the participants were required to reproduce $10 \%$ of body weight and were provided training to do so. The finding of significant differences only during non-dominant use of a walking cane suggests that this may be secondary to participants' varying ability to control the $10 \%$ loading task on this side.

These results imply the requirement of additional training in the test condition that requires partial weight bearing on the non-dominant hand side. However, the hand dominance or preferred hand does not have any effect on the gait parameters

when used for balance. The findings also suggest that the use of a cane does not modify the base of support when used for balance; however, it alters the swing and stance time of the ipsilateral side. When prescribing a cane as a supportive device for patients with weakness or pain, it needs to be understood that the use of a cane in healthy adults increases the stance phase on the contralateral side and swing phase on the ipsilateral side in addition to the decrease in the base of support. 


\section{Strengths and Limitations}

Although the study used a small sample, the repeated measures design enabled valid testing of the hypothesis. The wide confidence intervals for the mean difference of some variables, especially support conditions ( $\mathrm{C} 4$ and $\mathrm{C} 5$ ), are possibly due to the small sample included in the study. The participants were all healthy adults, and, thus, the results need to be applied with due caution to clinical populations.

\section{CONCLUSION}

The use of walking aids for balance does modify the swing and stance parameters of the ipsilateral side and does not affect the base of support formed by the feet in healthy adults. When used for support, walking aids alter the swing and stance parameters, and also the base of support formed by the feet. The hand dominance does not influence gait parameters when used for balance but does have some effect when used for support. Future investigations on the use of walking aids for support and balance could further understanding of the effects of walking aids on gait parameters and could provide important baseline data for studies that investigate rehabilitation interventions because, currently, it is not possible to identify whether changes in gait are due to rehabilitation interventions or the normal adaptations that occur when using a walking aid.

\section{REFERENCES}

1. Bateni H, Maki BE. Assistive devices for balance and mobility: Benefits, demands, and adverse consequences. Arch Phys Med Rehabil 2005;86: 134-145.

2. Brault MW. Americans with Disabilities: 2010. Report P70-131. Washington, DC: U.S. Department of Commerce; 2012.

3. Dean E, Ross J, Yack HJ, Paoni L. Relationships among cane fitting, function, and falls. Phys Ther 1993;73:494-504.

4. Engel J, Amir A, Messer E, Caspi I. Walking cane designed to assist partial weight bearing. Arch Phys Med Rehabil 1983;64:386-388.

5. Laufer Y. The effect of walking aids on balance and weight-bearing patterns of patients with hemiparesis in various stance positions. Phys Ther 2003;83:112-122.

6. Tagawa Y, Shiba N, Matsuo S, Yamashita T. Analysis of human abnormal walking using a multi-body model: Joint models for abnormal walking and walking aids to reduce compensatory action. J Biomech 2000;33: 1405-1414

7. Joyce BM, Kirby RL. Canes, crutches and walkers. Am Fam Physician 1991;43:535-542.

8. Ajemian S, Thon D, Clare P, Kaul L, Zernicke RF, Loitz-Ramage B. Cane-assisted gait biomechanics and electromyography after total hip arthroplasty. Arch Phys Med Rehabil 2004;85:1966-1971.

9. Neumann DA. An electromyographic study of the hip abductor muscles as subjects with a hip prosthesis walked with different methods of using a cane and carrying a load. Phys Ther 1999;79: 1163-1176.

10. Gitlin LN, Burgh D. Issuing assistive devices to older patients in rehabilitation: An exploratory study. Am J Occup Ther 1995;49: 994-1000.

11. Mann WC, Hurren D, Tomita M. Comparison of assistive device use and needs of home-based older persons with different impairments. Am J Occup Ther 1993;47:980-987.

12. Ashton-Miller JA, Yeh MWL, Richardson JK, Galloway T. A cane reduces loss of balance in patients with peripheral neuropathy: Results from a challenging unipedal balance test. Arch Phys Med Rehabil 1996; 77:446-452.

13. Kloos AD, Kegelmeyer DA, White SE, Kostyk SK. The impact of different types of assistive devices on gait measures and safety in Huntington's disease. PLoS One 2012;7:e30903.

14. Guild JR, Liu H, Connors M, Holmes C. Comparison of gait while ambulating with three different types of canes with normal subjects: A pilot study. Int J Ther Rehabil Res $2012 ; 1: 1$. 
15. Crosbie J. Muscle activation patterns in aided gait. Clin Rehabil 1993;7: 229-238.

16. Sorsdahl AB, Moe-Nilssen R, Strand LI. Test-retest reliability of spatial and temporal gait parameters in children with cerebral palsy as measured by an electronic walkway. Gait Posture 2008;27:43-50.

17. Paterson KL, Hill KD, Lythgo ND, Machette W. The reliability of spatiotemporal gait data for young and older women during continuous overground walking. Arch Phys Med Rehabil 2008;89:2360-2365.

18. Menz HB, Latt MD, Tiedemann A, Kwan MMS, Lord SR. Reliability of the GAITRite_ walkway system for the quantification of temporospatial parameters of gait in young and older people. Gait Posture 2004; 20:20-25.

19. Oldfield RC. The assessment and analysis of handedness: The Edinburgh Inventory. Neuropsychologia 1971;9:97-113.

20. Milenkovic S, Dragovic M. Modification of the Edinburgh Handedness Inventory: A replication study. Laterality 2013;18:340-348.

21. Schneiders AG, Sullivan SJ, O’Malley KJ, Clarke SV, Knappstein SA, Taylor LJ. A valid and reliable clinical determination of footedness. PMR 2010;2:835-841.

22. Hollman JH, McDade EM, Petersen RC. Normative spatiotemporal gait parameters in older adults. Gait Posture 2011;34:111-118.

23. GAITRite Manual. Peekskill, NY: CIR Systems; 2011.

24. Mathiyakom W, McNitt-Gray JL. Motor gait and falls. In: Squire LR, ed. Encyclopedia of Neuroscience. Philadelphia, PA: Elsevier; 2010, $1009-1013$.

25. Lugade V, Lin V, Chou LS. Center of mass and base of support interaction during gait. Gait Posture 2011;33:406-411. 
Table 1. Mean (SD) of the temporal and distance parameters of gait for all walking conditions

\begin{tabular}{|c|c|c|c|c|c|}
\hline Variables & Condition 1 & Condition 2 & Condition 3 & Condition 4 & Condition 5 \\
\hline Cadence & $111.87(12.18)$ & $100.59(14.56)$ & $100.35(14.03)$ & $82.74(15.42)$ & $79.81(14.32)$ \\
\hline \multicolumn{6}{|l|}{ Base of support (cms) } \\
\hline left/contralateral foot & $9.25(3.20)$ & $9.78(2.93)$ & $9.94(3.43)$ & $10.85(2.08)$ & $10.48(2.72)$ \\
\hline right/ipsilateral foot & $9.24(3.23)$ & $9.86(3.01)$ & $9.97(3.38)$ & $10.81(2.79)$ & $10.44(2.73)$ \\
\hline \multicolumn{6}{|l|}{ Swing time (\% gait cycle) } \\
\hline left/contralateral foot & $37.84(1.52)$ & $37.33(2.06)$ & $37.39(2.03)$ & $35.90(2.82)$ & $35.74(3.42)$ \\
\hline right/ipsilateral foot & $37.69(1.62)$ & $36.70(2.11)$ & $36.69(2.10)$ & $36.23(2.97)$ & $36.22(4.09)$ \\
\hline \multicolumn{6}{|l|}{ Stance time (\% gait cycle) } \\
\hline left/contralateral foot & $62.17(1.51)$ & $62.68(2.07)$ & $62.61(2.03)$ & $64.09(2.83)$ & $64.27(3.42)$ \\
\hline right/ipsilateral foot & $62.32(1.62)$ & $63.30(2.11)$ & $63.31(2.10)$ & $63.77(2.96)$ & $63.78(4.09)$ \\
\hline \multicolumn{6}{|c|}{ Single limb support ( $\%$ gait cycle) } \\
\hline left/contralateral foot & $37.70(1.66)$ & $36.71(2.11)$ & $36.70(2.10)$ & $36.25(3.02)$ & $36.15(4.07)$ \\
\hline right/ipsilateral foot & $37.84(1.52)$ & $37.32(2.06)$ & $37.37(2.02)$ & $35.90(2.82)$ & $35.82(3.46)$ \\
\hline \multicolumn{6}{|c|}{ Double limb support (\% gait cycle) } \\
\hline left/contralateral foot & $24.58(3.05)$ & $26.04(4.04)$ & $26.01(3.84)$ & $27.86(5.30)$ & $27.99(6.29)$ \\
\hline right/ipsilateral foot & $24.59(3.04)$ & $26.03(4.03)$ & $26.01(3.86)$ & $27.78(5.28)$ & $28.06(6.27)$ \\
\hline
\end{tabular}

Note. Left/right for condition 1; contralateral/ipsilateral for cane conditions (2 to5); Condition 1 - normal walking; Condition 2 - walking with a cane on the dominant hand for balance; Condition 3 - walking with a cane on the non-dominant hand for balance; Condition 4 - walking with a cane on the dominant hand while allowing approximately $10 \%$ of the body weight through the cane; Condition 5 - walking with a cane on the non- dominant hand while allowing approximately $10 \%$ of the body weight through the cane. 
Table 2. Summary of repeated measures ANOVA and pairwise comparisons for balance and support conditions

\begin{tabular}{|c|c|c|}
\hline \multirow[t]{2}{*}{ Variables } & Cane for balance & Cane for support \\
\hline & Condition $1,2 \& 3$ & Condition $1,4 \& 5$ \\
\hline \multirow[t]{3}{*}{ Cadence } & $\mathrm{F}(1,26)=35.87 ; \mathrm{p}<.001$ & $\mathrm{~F}(1,26)=126.01 ; \mathrm{p}<.001$ \\
\hline & $\mathrm{C} 1-\mathrm{C} 2: \mathrm{MD}=11.28[7.11,15.46] ; \mathrm{p}<.001$ & $\mathrm{C} 1-\mathrm{C} 4: \mathrm{MD}=29.14[23.12,35.16] ; \mathrm{p}<.001$ \\
\hline & C1-C3: MD = $11.52[6.90,16.14] ; p<.001$ & $\mathrm{C} 1-\mathrm{C} 5: \mathrm{MD}=32.07[25.09,39.05] ; \mathrm{p}<.001$ \\
\hline \multicolumn{3}{|l|}{ Base of support } \\
\hline \multirow[t]{3}{*}{ left/contralateral foot } & $\mathrm{F}(1,26)=2.50 ; \mathrm{p}=.12$ & $\mathrm{~F}(1,26)=11.98 ; \mathrm{p}<.001$ \\
\hline & & $\mathrm{C} 1-\mathrm{C} 4: \mathrm{MD}=-2.06[-3.30,-0.81] ; \mathrm{p}=.001$ \\
\hline & & $\mathrm{C} 1-\mathrm{C} 5: \mathrm{MD}=-1.68[-2.93,-0.44] ; \mathrm{p}=.006$ \\
\hline \multirow[t]{3}{*}{ right/ipsilateral foot } & $\mathrm{F}(1,26)=3.08 ; \mathrm{p}=.08$ & $\mathrm{~F}(1,26)=10.82 ; \mathrm{p}<.001$ \\
\hline & & $\mathrm{C} 1-\mathrm{C} 4: \mathrm{MD}=-2.02[-3.29,-0.76] ; \mathrm{p}=.001$ \\
\hline & & $\mathrm{C} 1-\mathrm{C} 5: \mathrm{MD}=-1.65[-2.97,-0.33] ; \mathrm{p}=.01$ \\
\hline
\end{tabular}

\section{\% Swing time}

left/contralateral foot $\quad \mathrm{F}(1,26)=2.26 ; \mathrm{p}=.12 ;$

$\mathrm{F}(1,26)=7.42 ; \mathrm{p}=.002 ;$

C-C4: $\mathrm{MD}=1.92[0.78,3.07] ; \mathrm{p}=.001$

C1-C5: $\mathrm{MD}=2.09[0.32,3.85] ; \mathrm{p}=.02$ 

right/ipsilateral foot
$\mathrm{F}(1,26)=10.41 ; \mathrm{p}<.001$
$\mathrm{F}(1,26)=3.85 ; \mathrm{p}=.03$
C1-C2: $\mathrm{MD}=0.99[0.35,1.63] ; \mathrm{p}=.002$
C1-C4: $\mathrm{MD}=1.44[0.11,2.78] ; \mathrm{p}=.03$
C1-C3: $\mathrm{MD}=1.00[0.27,1.73] ; \mathrm{p}=.005$

\begin{tabular}{lll}
\hline $\begin{array}{l}\text { \% Stance time } \\
\text { left/contralateral foot }\end{array}$ & $\mathrm{F}(1,26)=2.26 ; \mathrm{p}=.12$ & $\mathrm{~F}(1,26)=7.39 ; \mathrm{p}=.002$ \\
& & $\mathrm{C} 1-\mathrm{C} 4: \mathrm{MD}=-1.91[-3.06,-0.76] ; \mathrm{p}=.001$ \\
right/ipsilateral foot & $\mathrm{F}(1,26)=10.41 ; \mathrm{p}<.001$ & $\mathrm{C} 1-\mathrm{C} 5: \mathrm{MD}=-2.09[-3.86,-0.33] ; \mathrm{p}=.02 ;$ \\
& $\mathrm{C} 1-\mathrm{C} 2: \mathrm{MD}=-0.99[-1.62,-0.35] ; \mathrm{p}=.001$ & $\mathrm{~F}(1,26)=3.83 ; \mathrm{p}=.03$ \\
& $\mathrm{C} 1-\mathrm{C} 3: \mathrm{MD}=-1.00[-1.73,-0.27] ; \mathrm{p}=.005$ & \\
\hline $\begin{array}{l}\text { \% Single limb support } \\
\text { left/contralateral foot }\end{array}$ & $\mathrm{F}(1,26)=10.61 ; \mathrm{p}<.001$ & $\mathrm{~F}(1,26)=3.96 ; \mathrm{p}=.03 ;$ \\
& $\mathrm{C} 1-\mathrm{C} 2: \mathrm{MD}=1.00[0.36,1.63] ; \mathrm{p}=.001$ & $\mathrm{C} 1-\mathrm{C} 4: \mathrm{MD}=1.42[0.08,2.75] ; \mathrm{p}=.03$ \\
& $\mathrm{C} 1-\mathrm{C} 3: \mathrm{MD}=1.00[0.27,1.73] ; \mathrm{p}=.005$ & \\
& $\mathrm{~F}(1,26)=2.31 ; \mathrm{p}=.11$ & $\mathrm{~F}(1,26)=7.12 ; \mathrm{p}=.002$ \\
& & $\mathrm{C} 1-\mathrm{C} 4: \mathrm{MD}=1.95[0.79,3.11] ; \mathrm{p}=.001$ \\
& & $\mathrm{C} 1-\mathrm{C} 5: \mathrm{MD}=2.03[0.25,3.81] ; \mathrm{p}=.02$
\end{tabular}


\% Double limb support

left/contralateral foot

$$
\mathrm{F}(1,26)=7.94 ; \mathrm{p}=.003
$$

C1-C2: $\mathrm{MD}=-1.45[-2.70,-0.18] ; \mathrm{p}=.02$

C1-C3: $\mathrm{MD}=-1.43[-2.60,-0.26] ; \mathrm{p}=.02$

right/ipsilateral foot

$$
\mathrm{F}(1,26)=7.94 ; \mathrm{p}=.04
$$

C1-C2: $\mathrm{MD}=-1.44[-2.70,-0.18] ; \mathrm{p}=.02$

C1-C3: $\mathrm{MD}=-1.42[-2.60,-0.24] ; \mathrm{p}=.02$
$\mathrm{F}(1,26)=8.43 ; \mathrm{p}=.001$

C1-C4: $\mathrm{MD}=-3.29[-5.50,-1.07] ; \mathrm{p}=.003$

C1-C5: $\mathrm{MD}=-3.42[-6.18,-0.66] ; \mathrm{p}=.01$

$\mathrm{F}=8.63 ; \mathrm{p}=.001$

C1-C4: $\mathrm{MD}=-3.18[-5.34,-1.02] ; \mathrm{p}=.003$

C1-C5: $\mathrm{MD}=-3.46[-6.19,-0.74] ; \mathrm{p}=.01$

Note. $\mathrm{ANOVA}=$ analysis of variance. $\mathrm{C}=$ walking condition; $\mathrm{C} 1=$ normal walking; $\mathrm{C} 2=$ walking with a cane in the dominant hand for balance; $\mathrm{C} 3=$ walking with a cane in the non-dominant hand for balance; $\mathrm{C} 4=$ walking with a cane in the dominant hand while allowing approximately $10 \%$ of the body weight through the cane; C5 = walking with a cane on the non-dominant hand while allowing approximately $10 \%$ of the body weight through the cane. 